Sulisworo D. (2012). Model Kepemimpinan Modern di Program Pascasarjana Universitas Ahmad Dahlan. Journal of Education and Learning. Vol.6 (1) pp. 43-50.

\title{
Model Kepemimpinan Modern di Program Pascasarjana Universitas Ahmad Dahlan
}

\author{
Dwi Sulisworo* \\ Universitas Ahmad Dahlan
}

\begin{abstract}
In the management of higher education, demand a change can be done effectively when the leadership and management are well developed. In general, internal conflicts in the education management occurred due to poor leadership. This study is a qualitative study with a phenomenological approach. The subject of the study is Graduate Program of University Ahmad Dahlan which manages five master programs. Determination of each of people which considers his/her competence, knowledge, experience and personal attributes will affect to performance and operational leadership roles, organizational, and public. Cross-departmental activities and external parties become a focus for leadership in achieving the vision and mission of the organization.
\end{abstract}

Keywords: leadership, organization, quality assurance, higher education

\begin{abstract}
Abstrak
Dalam pengelolaan pendidikan tinggi, tuntutan perubahan dapat dilakukan secara efektif ketika kepemimpinan dan tatakelola dikembangkan dengan baik. Berbagai konflik internal dalam pengelolaan pendidikan pada umumnya terjadi karena kepemimpinan yang kurang baik. Penelitian ini merupakan penelitian kualitatif dengan pendekatan fenomenologis. Penelitian ini menggunakan subyek program Pascasarjana di Universitas Ahmad Dahlan yang mengelola 5 program studi S2. Penentuan personil yang mempertimbangkan kompetensi, pengetahuan, pengalaman dan atribut personal akan dapat mempengaruhi kinerja dan peran kepemimpinan operasional, organisasional, dan publik. Aktivitas yang bersifat lintas departemen dan juga dengan pihak eksternal menjadi fokus bagi kepemimpinan dalam mencapai visi dan misi organisasi.
\end{abstract}

Kata kunci: kepemimpinan, organisasi, penjaminan mutu, pendidikan tinggi

*Dwi Sulisworo, Program Pascasarjana Manajemen Pendidikan, Universitas Ahmad Dahlan,

Jl. Kapas No. 9, Yogyakarta 55164. E-mail: dwi@uad.ac.id 


\section{Pendahuluan}

Berkembangnya tuntutan kualitas dan juga dorongan teknologi dalam berbagai bidang, menjadikan perguruan tinggi harus terus menerus berkembang untuk dapat menghasilkan produkproduk akademik yang berguna bagi masyarakat. Dalam pengelolaan pendidikan tinggi, tuntutan perubahan tersebut dapat dilakukan secara efektif ketika kepemimpinan dan tatakelola dikembangkan dengan baik. Berbagai konflik internal dalam pengelolaan pendidikan pada umumnya terjadi karena kepemimpinan yang kurang baik.

Isu strategis pendidikan tinggi yang tertulis dalam HELTS (Higher Education Long Term Strategy) adalah pada pencapaian kualitas dengan didukung 4 pilar yaitu: akuntabilitas, otonomi, evaluasi, dan akreditasi. Penjabaran isu ini pada level perguruan tinggi adalah bagaimana mendorong perguruan tinggi untuk mampu merancang kegiatan yang berorientasi pada pencapaian kinerja yang ditentukan. Peran pimpinan perguruan tinggi dalam mengelola dan mengatur institusi dan juga peran nyata dari pimpinan ini akan sangat menentukan keberhasilan institusi pendidikan. Kemampuan kepemimpinan dalam penentuan kebijakan pada bidang apa yang akan secara signifikan mendongkrak kinerja akan dapat menjadi arah bagi struktur yang lebih rendah. Sistem pengelolaan institusi pendidikan yang mampu mengelola indikator kinerja akan dapat menyatukan semua aktivitas organisasi menjadi gerakan bersama mencapai visi organisasi.

Beberapa permasalahan yang ditemui dalam pengelolaan institusi pendidikan adalah bagaimana memastikan bahwa kinerja yang ditetapkan oleh organisasi pada level atas dapat diturunkan menjadi kinerja pada level yang lebih rendah, bagaimana menentukan indikator kinerja kunci yang terdukung oleh indikator lain yang saling berpengaruh, bagaimana mengukur indikator kunci yang telah ditentukan. Kemampuan organisasi untuk menentukan dan mengelola kinerja dengan memperhatikan indikator-indikator yang ditentukan tersebut sangat tergantung pada kepemimpinan dan tata kelola institusi pendidikan. Tulisan ini berusaha mengungkap model kepemimpinan dan tatakelola seperti apa yang efektif untuk dapat membangun institusi pendidikan yang unggul dalam persaingan.

\section{Kajian Kepemimpinan Akademik Pada Pendidikan Tinggi}

Dewasa ini, dalam era ekonomi pengetahuan, modal dan aset tangible merupakan kebutuhan sekunder dalam organisasi. Pengetahuan merupakan sumber utama untuk daya saing dan inovasi. Pendidikan tinggi merupakan institusi yang bergerak dalam pengetahuan yang aktivitas intinya terkait dengan penciptaan dan diseminasi pengetahuan, serta pembelajaran (Cranfield and Taylor, 2008; Yeh, 2005). Dengan perubahan lingkungan organisasi tersebut, maka respon dan antisipasi manajemen dan kepemimpinan yang dilakukan oleh perguruan tinggi juga harus berubah termasuk dalam pengelolaan program pasca sarjana sebagai bagian dari perguruan tinggi. Hal ini juga akan berpengaruh pada bagaimana metodologi pembelajaran sebagai layanan utama perguruan tinggi dikelola (Cano, 2011); termasuk di dalamnya adalah bagaimana teknologi dapat mempengarui perilaku, budaya, dan juga cara berfikir mahasiswa (Craig and Amernic, 2006). Akuntabilitas pada pendidikan tinggi telah menjadi isu yang menantang bagi institusi pendidikan tinggi. Sebagai kelanjutan dari isu ini, pendidikan tinggi memerlukan konsep-konsep baru tentang pengelolaan termasuk bagaimana menentukan indikator kierja yang baik sesuai dengan nilai-nilai yang dikembangkan bagi organisasi, alumni, mahasiswa dan stakeholder eksternal.

Institusi pendidikan tinggi saat ini menghadapi dunia yang lebih saling terkoneksi baik dalam pengetahuan, kreativitas, dan inovasi sebagai sesuatu elemen penting dalam perubahan masyarakat. Tekanan dunia global yang seperti ini, dicirikan pada dua hal percepatan dalam pertumbuhan masyarakat ilmu pengetahuan yang memiliki kecenderungan pada penguatan teknologi informasi dan komunikasi dan yang kedua adalah proses percepatan dan inovasi yang membawa pada ketidakpastian identitas, dunia kerja maupun karir. Dengan situasi ini maka institusi pendidikan tinggi di hampir semua bagian dunia berusaha mencari berbagai cara dalam memelihara keberlanjutannya (Shephard, 2008). Shephard (2008) juga menyatakan bahwa institusi pendidikan tinggi yang mengusahakan pada outcome yang terkait dengan keberlanjutan lingkungannya sangat berbeda-beda secara nyata (. Sehingga keunikan suatu pendidikan dalam pengelola organisasinya menjadi sangat berbeda-beda pula.

Pendidikan tinggi terutama universitas atau perguruan tinggi merupakan instrumen utama dalam masyarakat untuk secara terus menerus menciptakan pengetahuan. Manajemen pengetahuan pada perguruan tinggi yang mengelola personil, proses, dan teknologi akan sangat menentukan keberhasilannya dalam melayani masyarakat pengetahuan. Ada dua jenis pengetahuan yang ada pada pendidikan tinggi, yaitu pengetahuan akademik dan pengetahuan organisasi. Pengetahuan akademik merupakan tujuan utama pendidikan tinggi. Sedangkan pengetahuan organisasi adalah pengetahuan terkait dengan seluruh bisnis yang ada dalam institusi seperti kekuatan dan kelemahan, faktor kunci 
kritis organisasi, atau pengguna yang dilayani (Yeh, 2005). Perubahan yang terjadi pada lingkungan strategis ini telah menyebabkan tuntutan untuk perubahan peran pimpinan pendidikan tinggi (Singh and Purohit, 2010)

Kepemimpinan akademik pada pendidikan tinggi merupakan sesuatu yang sangat dinamis. Ada dua model kepemimpinan yang diterapkan pada pendidikan tinggi yaitu kepemimpinan transaksional dan kepemimpinan transformasional (Koen and Bitzer, 2010). Teori kepempimpinan transaksional menyatakan bahwa kepemimpinan ini merupakan proses negosiasi berdasar pada keseimbangan kekuasaan (power) yang dimiliki pemimpin dan pengikut. Sebagai konsekuensi, keberhasilan kepemimpinan tergantung pada hukuman atau penghargaan yang memungkinkan individu melakukan perubahan. Hal ini juga dapat terkait dengan kepemimpinan yang diarahkan secara kolektif dimana kekuasaan untuk mengendalikan para pengukit untuk bersama-sama mencapai tujuan (Bono and Judge, 2004; Bass, et all., 2003). Kepemimpinan transformasional memberikan penekanan pada kemampuan untuk memberikan inspirasi dan kemampuan untuk memotivasi komunitas agar dapat merespon perubahan secara efektif (Bass, et all., 2003; Lievens, et all., 1997). Kepemimpinan ini pada institusi pendidikan tinggi akan mampu membawa pengikutnya mencapai kinerja yang lebih baik (Leisyte, et all., 2009). Dalam pengelolaan internasionalisasi program akademik, kepemimpinan dalam integrasi akademik dan sosial pada mahasiswa akan berpengaruh pada kinerja mahasiswa (Rienties, et all., 2011).

\section{Metode penelitian}

Penelitian ini merupakan penelitian kualitatif dengan pendekatan fenomenologis dimana peneliti masuk dalam proses yang diteliti. Teknik kualitatif dipakai sebagai pendekatan dalam penelitian ini, karena teknik ini untuk memahami realitas rasional sebagai realitas subjektif khususnya warga sekolah. Proses observasi dan wawancara mendalam bersifat sangat utama dalam pengumpulan data.

Penelitian ini menggunakan subyek program pascasarjana di Universitas Ahmad Dahlan yang mengelola 5 program studi S2. Sumber data diperoleh dari wacana dan pembicaraan yang berkembang di lingkungan yang diteliti dan dokumen yang dipelihara organisasi. Wacana yang terjadi diperoleh dalam interaksi dengan pihak internal dan relatif tidak menggunakan data dari wacana eksternal. Pihak internal mencakup personil pada pimpinan program pascasarjana, pimpinan program studi, karyawan, unit terkait dengan program pasca di lingkunan universitas, dan mahasiswa. Data terkait dengan dokumen mencakup standard operation procedure yang digunakan di program pasca sarjana, pedomanpedoman pengelolaan yang disosialisasikan pada stakeholder, surat-surat komunikasi ke internal dan eksternal. Dengan menggunakan kedua sumber data tersebut dilakukan sebuah konstruksi konsep tentang kepemimpinan yan berjalan di subyek yang diteliti, sehingga dapat dilihat peta atau model kepemimpinan dalam pengelolaan organisasi.

Tahap-tahap dalam pengumpulan data dalam penelitian ini menckup tahap orientasi, tahap ekplorasi dan tahap member check. Tahap orientasi, dalam tahap ini yang dilakukan peneliti adalah melakukan orientasi pada program pascasarjana dengan melakukan interaksi pada personil yang ada di lingkungan yang diteliti. Selanjutnya dilakukan studi dokumentasi untuk melihat dan mencatat data yang diperlukan terkait penelitian ini. Tahap eksplorasi, tahap ini merupakan tahap pengumpulan data di lokasi penelitian, dengan melakukan wawancara dengan unsur-unsur yang terkait. Tahap member check, setelah data diperoleh di lapangan, baik melalui observasi, wawancara ataupun studi dokumentasi, maka data yang ada tersebut diangkat dan dilakukan audit trail yaitu menchek keabsahan data sesuai dengan sumber aslinya.

\section{Hasil dan Pembahasan \\ Karakteristik Kepemimpinan Program Pascasarjana}

Kepemimpinan efektif mengarahkan dan mempengaruhi perilaku semua unsur dalam program studi dan program lainnya, mengikuti nilai, norma, etika, dan budaya organisasi yang disepakati bersama, serta mampu membuat keputusan yang tepat dan cepat. Kepemimpinan mampu memprediksi masa depan, merumuskan dan mengartikulasi visi yang realistik, kredibel, serta mengkomunikasikan visi ke depan, yang menekankan pada keharmonisan hubungan manusia dan mampu menstimulasi secara intelektual dan arif bagi anggota untuk mewujudkan visi organisasi, serta mampu memberikan arahan, tujuan, peran, dan tugas kepada seluruh unsur dalam perguruan tinggi.

Kepemimpinan operasional, organisasi, dan publik merupakan kepemimpinan yang sifatnya integratif dan komprehensif yang tidak dapat secara mudah dipisahkan secara mutual exclusive. Bagaimana kemampuan seorang pemimpin untuk mengatur keseimbangan ketiga jenis kepemimpinan 
tersebut akan menentukan keberhasilan mencapai visi dan misi organisasi secara baik. Tiga aspek yang perlu diperhatikan untuk dapat terbentuk kepemimpinan yang baik, yaitu kompetensi, pengalaman, dan atribut personal.

\section{Kompetensi}

Kompetensi yang harus dimiliki oleh pemimpin adalah kemampun inovasi dan berfikir "out-ofthe-box" ketika mengenalkan dan mengelola perubahan. Selain juga harus memiliki kemampuan untuk mengembangkan kerjasama internal yang kuat antar unit kerja dan kelompok kerja yang ada, serta membangun hubungan startegis dengan pihak luar untuk memastikan pihak berkepentingan terpenuhi kebutuhan mereka. Dalam komunitas yang luas (public community) seorang pimpinan juga harus memiliki kompetensi untuk berkomunikasi dengan baik, memberi inspirasi dan memimpin perubahan pada skala lebih luas dari unit kerjanya sendiri, kesabaran untuk mencapai hasil, mendorong pada kinerja yang tinggi di semua level.

\section{Pengetahuan}

Pengetahuan yang harus dimiliki agar kepemimpinan dapat menjalankan kepemimpinan operasional, organisasi, dan publik adalah pemahaman yang mendalam terkait model dan framework bisnis proses organisasi, peta finansial dan sumber daya dalam persaingan. Pemahaman ini juga pada pemahaman proses, layanan, dan prosedur akademik di level lebih rendah secara keseluruhan. Keimpinan ini juga harus memiliki pengetahuan untuk melakukan perencanaan dan memahami kebutuhan pihak berkepentingan serta persaingan yang terjadi dalam membangun organisasi yang kuat. Selain itu juga pemahaman yang baik dalam fungsi manajemen seperti kompensasi, pelatihan, dan manajemen kinerja dan pengukuran.

\section{Pengalaman}

Pengalaman yang harus dimiliki oleh pemimpin untuk mencapai visi dan misi organisasi adalah pengalaman pada bidang berikut: memimpin unit kerja dengan melakukan akuntabilitas keungutungan dan kerugian, bekerja dalam kelompok lintas fungsi, penyiapan suatu perencanaan, mengelola suatu fungsi yang penting secara akademik. Selain itu, pada level strategis, perlu pernah terlibat dalam menciptakan budaya organisasi, pengendalian biaya, dan tugas keluar dalam membangun kerjasama. Hal ini penting karena pemimpin pascasarjana harus memberikan arah membangun budaya organisasi di lingkungannya.

\section{Atribut Personal}

Atribut personal untuk kepemimpinan adalah perlu dapat menerima feedback, dapat secara fleksible dan adapatif terhadap perubahan, dan memiliki keinginan yang kuat untuk pengembangan dan pertumbuhan berkelanjutan, dan berani mengambil risiko. Akhirnya, pemimpin juga menunjukkan tingkat ambisi, imajinasi, inovasi, dan orientasi untuk belajar yang tinggi.

\section{Kepemimpinan Operasional}

Kepemimpinan operasional adalah kepemimpian yang berkaitan dengan kemampuan menjabarkan visi, misi ke dalam kegiatan operasional program studi di lingkungan pascasarjana. Penjabaran visi, misi ditunjukkan dalam rencana strategis dan rencana operasional hingga pada aktivitas perencanaan tindakan tahunan. Pimpinan pascasarjana melakukan penjabaran ini dalam suatu workshop bersama dengan para ketua program studi, dekan fakultas terkait, dosen di lingkungan pascasarjana.

\section{Operasional Perencanaan}

Pada tiap awal tahun akademik, program pasca sarjana mengembangkan rencana implementasi program tahunan yang juga mencakup rencana tahunan program studi. Rencana implementasi program ini selanjutnya disahkan oleh pimpinan untuk diusulkan ke universitas dalam proses negocosting dan negoaktivitas. Ukuran dalam negocosting dan negoaktivitas adalah efektivitas rencana aktivitas dalam mendukung tujuan dan sasaran mutu universitas.

Setelah pengesahan rencana anggaran dan belanja universitas (RAPBU) disahkan oleh Majelis Dikti Muhamadiyah, pimpinan pascasarjana memiliki kemandirian penuh dalam mengelola sumber daya untuk mendukung operasional pasca agar strategi yang dicanangkan dapat berjalan sesuai rencana untuk mencapai tujuan organisasi. Koordinasi internal di program pascasarjana dilakukan setelah pengesahan RAPBU sehingga setiap unit dilingkungan kerja memiliki kontrak manajemen yang berisi sasaran atau performance indicators program studi untuk dijalankan sesuai perencanaan program yang telah dikembangkan oleh program studi. Monitoring dan evaluasi (monev) implementasi program ini dilakukan dengan bantuan team monev yang dibentuk oleh Badan Penjaminan Mutu di universitas. 
Monev dilakukan untuk melihat serapan anggaran dan efektivitas program dalam mencapai sasaran mutu. Hasil dari monev ini digunakan oleh pimpinan untuk melakukan penyesuain dan perbaikan implementasi program agar lebih efektif.

\section{Operasional Implementasi}

Dalam impementasi program di lingkungan pascasarjana, standard operation procedure (SOP) digunakan sebagai panduan agar semua aktivitas dapat transparan, akuntabel, dan dapat ditelusuri ketika terjadi ketidaksesuaian dengan mutu yang diharapkan. Semua SOP yang ada merupakan dokumen terkendali yang diatur dalam sistem pengelolaan dokumen mutu. Pada level program pascasarjana, pengendali sistem mutu pasca berperan membantu pimpinan dalam memastikan semua proses bisnis akademik berjalan sesuai SOP. Pelaksanaan SOP yang bersifat operasional dan teknis dilakukan secara terdistribusi ke program studi pasca sarjana sesuai kewenangan yang telah diatur dalam SOP terkait. Rapat koordinasi semesteran dilakukan untuk memonitor apakah proses akademik sudah berjalan.

Kesesuaian proses akademik dengan SOP akan dilihat melalui Audit Mutu Internal (AMI) secara periodik tiap semester secara independen yang dilakukan oleh Badan Penjaminan Mutu. Laporan AMI akan disampaikan kepada pimpinan pascasarjan sebagai dokumen hasil AMI. Sedangkan temuan yang diperoleh dari AMI akan disampaikan kepada rektor untuk dibawa dalam rapat tinjauan manajemen (RTM) universitas agar dapat diputuskan bersama tindakan perbaikan secara terukur. Untuk mendukung efektivitas dan efisiensi implementasi program dalam aktivitas harian, pimpinan pascasarjana didukung dengan berbagai sistem informasi yang memadai selain staf yang memenuhi kualifikasi dan kompetensi sesuai standar (Lihat dapam SOP SDM).

\section{Operasional Komunikasi dan Evaluasi}

Komunikasi di lingkungan pascasarjana dilakukan dalam berbagai modus. Selain rapat koordinasi, saluran komunikasi juga dilakukan melalui web program pascasarjana, web program studi, email individu maupun email resmi kantor, dan portal dosen yang dapat berupa office note, surat keputusan, edaran, maupun pengumuman. Untuk hal-hal yang sifatnya krusial dan mendadak, pimpinan juga dapat melakukan rapat khusus agar permasalahan segera dapat diantisipasi dengan baik.

Evaluasi kinerja unit maupun staf dilakukan oleh pimpinan secara tahunan. Untuk unit kerja dilakukan dengan melihat capaian kinerja dalam mendukung sasaran kinerja program pascasarjana dan keefektifan implementasi strategi yang dicanangkan. Sedangkan evaluasi kinerja staf terutama dosen dilakukan dengan mencermati indeks kinerja dosen (IKD). IKD ini mencakup keberhasilan dosen dalam mengelola pembelajaran, pelaksanaan aktivitas penelitian dan pengabdian masyarakat dan juga moralitas keislaman (diatur dalam SOP ..). Hasil evaluasi ini selanjutnya akan digunakan untuk menentukan tindakan perbaikan bagi individu bersangkutan.

\section{Operasional Pemanfaatan Fasilitas}

Pengelolaan fasilitas yang bersifat jangka pendek seperti ruang kelas, laboratorium dan sarana prasarana belajar lain dilakukan oleh ketua program studi. Beberapa sistem informasi dimanfaatkan untuk pengelolaan fasilitas ini oleh program studi seperti SIA, SIAGA, SDM, simeru. Sedangkan untuk pengembangan fasilitas pascasarjana dilakukan oleh pimpinan pasca melalui komunikasi dengan univesitas dan BPH. Pembagian otoritas yang jelas ini dilakukan agar distribusi beban kerja menjadi lebih jelas dan terukur.

\section{Kepemimpinan Organisasi}

Kepemimpinan organisasi berkaitan dengan pemahaman tata kerja antar unit dalam organisasi perguruan tinggi. Peran kepemimpinan pascasarjana ini dilakukan dalam aktivitas koordinasi lintas fungsi dan struktur. Aspek yang dapat dilihat mencakup dalam pengelolaan dan perencanaan fasilitas dan infrastruktur, sumberdaya manusia, keuangan, dan penjaminan mutu.

\section{Koordinasi Pengelolaan dan perencanaan fasilitas dan infrastruktur}

Dalam pengelolaan dan perencanaan fasilitas dan infrastruktur, kepemimpinan yang dilakukan seperti dalam penentuan kapasitas yang akan digunakan untuk penyelenggaraan proses pembelajaran. Penentuan kebutuhan ruang kuliah, laboratorium, ruang kerja, dan ruang publik untuk perencanaan tahunan dilakukan melalui koordinasi dengan Biro Fasilitas dan Aset terutam pada Bidang Aset. Berdasarkan data time series terkait hal ini, dapat direncanakan program rekruitmen mahasiswa dalam beberapa tahun ke depan, tentu dengan mempertimbangkan faktor lain. Forecasting yang dilakukan tersebut selanjutnya digunakan untuk membantu universitas dalam pencapaian dan perencanaan sesuai masterplan yang ada. Proses komunikasi koordinasi ini merupakan wewenang BPH dan Rektor; 
sehingga pimpinan pascasarjana terlibat dalam penentuan kebijakan perencanaan bersama para dekan dan kepala unit kerja lain.

\section{Koordinasi Pengelolaan dan Perencanaan Sumberdaya Manusia}

Penentuan kebijakan lain yang dilakukan antar unit adalah dalam penentuan pengadaan sumber daya manusia. Trendwatching yang telah dilakukan oleh universitas dalam penataan dan perencanaan sumberdaya manusia merupakan rujukan dalam proses pengangkatan dan pemberhentian staff. Pimpinan pascasarjana menentukan kualifikasi dan jumlah kebutuhan staff yang memenuhi kebutuhan implementasi strategi. Selanjutnya kebutuhan ini dikomunikasikan dengan universitas untuk dapat dilakukan proses rekruitment sesuai periode yang ada. Dalam hal ini pimpinan pascasarjana memikili otoritas dalam menentukan apakah staf yang akan direkruit sesuai dengan kualifikasi atau tidak, meskipun dalam memutuskan merupakan otoritas dari BPH.

\section{Koordinasi Pengelolaan dan Perencanaan Keuangan}

Dalam pengelolaan keuangan, pimpinan pascasarjana memiliki otoritas pengelolaan sesuai dengan hasil negocosting yang ditetapkan dalam RAPBU oleh Majelis DIKTI Muhammadiyah. Sedangkan perencanaan keuangan dilakukan sebagaimana dijelaskan sebelumnya dilakukan dengan koordinasi internal bersama para kepala unit kerja di lingkungan pascasarjana. Dalam implementasi program yang telah disetujui untuk menjalankan strategi yang telah dicanangkan diatur dalam prosedur pencairan anggaran. Aktivitas yang akan diimplementasi dilengkapi dengan Term of Reference (TOR) agar hasil implementasi dapat transparan, akuntable, dan terukur keberhasilannya. ToR ini menjadi dasar pula bagi Bidang Finansial dan juga Unit Monev universitas dalam proses monitoring, evaluasi dan audit akademin/ non akademik sesuai periode yang ada.

Dalam implementasi suatu aktivitas, terkadang karena perubahan lingkungan strategis, aktivitas perlu dilakukan revisi. Hal ini berakibat pada kemungkinan perubahan besaran anggaran maupun perubahan aktivitas itu sendiri. Untuk aktivitas yang perlu dilakukan perbaikan seperti tersebut, pimpinan pascasarjana berhak melakukan dengan memperhatikan tingkat efektivitas dan efisiensi sumberdaya agar tidak menurunkan kinerja yang dicapai. Perubahan yang dilakukan oleh pimpinan pascasarjana selanjutnya dimintakan persetujuan dari universitas melalui wakil rektor I jika perubahan pada aktvitas dan melalui rektor II jika perubahan pada pemindahan alokasi anggaran.

\section{Koordinasi Penjaminan Mutu}

Pimpinan pascasarjana dalam implementasi penjaminan mutu di pascasarjana didukung oleh team Pengendali Sistem Mutu Pasca. Secara organisatoris team ini memiliki garis koordinasi dengan Badan Penjaminan Mutu, dan memiliki garis kendali di bawah Pimpinan Pascasarjana. Ada tiga aktivitas pimpinan dalam kepemimpinan organisasi yang terkait dengan penjaminan mutu, yaitu koordinasi dalam perencanaan mutu, implementasi mutu, dan audit mutu.

Dalam pengembangan berbagai prosedur dan instruksi kerja di lingkungan pasca, pimpinan pasca dan juga ketua program studi melakukan bersama dengan pimpinan fakultas dan juga program studi ataupun unit lain seperti biro dan lembaga tergantung pada jenis dokumen yang akan dilakukan. Perencanaan mutu yang paling pertema adalah penentuan kebijakan mutu dan sasaran mutu. Kebijakan mutu dan sasaran mutu level universitas harus dipahami dan dijadikan dasar oleh semua level termasuk di program pascasarjana. Proses penentuan sasaran mutu universitas melibatkan dan ditetapkan bersama oleh semua elemen di universitas dalam Rapat Tinjuan Manajemen Universitas dan dipimpin oleh rektor. Pada forum ini pimpinan pascasarjana berperan untuk bersama-sama pimpinan unit kerja lain memasukkan ide-ide perbaikan berkelanjutan yang paling efektif bagi kemajuan unit kerja yang dipimpinnya. Selain itu keterlibatan pimpinan pasca pada forum ini juga memungkinkan untuk dapat memahami lebih baik tujuan universitas dan dapat segera diimplementasi di level program pascasarjana. Koordinasi dalam implementasi mutu dalam mencapai sasaran mutu program pascasarjana yang sesuai dengan sasaran mutu universitas dilakukan dengan unit kerja lain di universitas. Beberapa jenis koordinasi seperti:

1. Koordinasi dengan Fakultas dan kantor universitas terkait untuk pencapaian sasaran mutu Indeks Kinerja Dosen. Beberapa hal yang perlu dikoordinasikan antara lain adalah pemantauan distribusi mengajar dosen, penggunaan laboratorium kesesuaian bidang imu bagi dosen yang akan studi lanjut.

2. Koordinasi dengan LPP dan Pusat Studi untuk penelitian dan Publikasi Karya ilmiah internasional sebagai salah satu sasaran mutu. Aktivitas yang dilakukan adalah penelitian interdisipliner, fasilitasi pelatihan untuk meraih hibah penelitian dari luar UAD, bantuan pendampingan penulisan jurnal internasional. 
3. Koordinasi kerjasama internasional dengan KUI. Beberapa koordinasi yang dilakukan seperti penyusunan template MoU dengan universitas asing.

4. Koordinasi dengan dengan BISKOM, dan BIFAS (Bidang Aset) yang terkait dengan pencapaian sasaran mutu pelayanan berbasis IT . Koordinasi yang dilakukan dari sejak pemetaan kompetensi internal pasca hingga implementasi penggunaan sistem informasi.

Sebagai tambahan informasi, koordinasi yang dilakukan oleh pimpinan pasca dalam implementasi sistem mutu tersebut merupakan koordinasi lintas fungsi dan departemen yang melibatkan baik fakultas, lembaga, biro maupun badan yang ada di UAD. Keterlibatan pimpinan pasca dalam forum tersebut untuk memastikan bahwa semua komponen organisasi di UAD berjalan pada jalur yang sama dan seiring untuk mencapai tujuan organisasi.

Audit mutu di UAD dilakukan setiap semester melalui Audit Mutu Internal (AMI), selain juga dilakukan kegiatan monitoring dan evaluasi. Kegiatan AMI dikendalikan oleh Badan Penjamin Mutu. Keterlibatan koordinasi yang dilakukan pimpinan pasca terjadi pada saat sosialisasi persiapan AMI, proses AMI, dan wrap up meeting AMI, maupun RTM untuk membahas temuan AMI.

\section{Kepemimpinan Publik}

Kepemimpinan publik berkaitan dengan kemampuan menjalin kerjasama dan menjadi rujukan bagi publik. Sebagaimana disebutkan dalam visi program pasca sajaran, kemanfaatan keilmuan bagi masyarakat luas menjadi salah satu ukuran keberhasilan. Untuk mendukung hal tersebut terutama dalam deseminasi ilmu pengetahuan, pemberian pengaruh perubahan dan keteladanan pada masyarakat akan menjadi arah bagaimana kepemimpinan publik dapat dibangun. Kegiatan yang terkait dengan kepemimpinan publik dilakukan pada jalur formal mapun nonformal.

Pada jalur formal akademik, kegiatan yang menunjukkan kepemimpinan publik antara lain: forum-forum diskusi dengan Dinas Pendidikan Propinsi untuk pengembangan program Vokasi, Focus Group Discussion untuk Desentralisasi Pendidikan, team pemantau independen ujian nasional, exper sharing untuk program active learning, dengan LPMP untuk persiapan program sertifikasi laboran sekolah, pemetaan guru-guru, pemetaan sistem penjaminan mutu sekolah, dengan MGMP, dengan Asosiasi profesi. Pada jalur non formal, kegiatan yang menunjukkan kepemimpinan publik antara lain peran dalam berbagai kepengurusan di persyarikatan Muhammadiyah, dan organisasi kemasyarakatan lain.

\section{Model Kepemimpinan}

Berdasarkan pada paparan hasil temuan pada kepemimpinan yang ada di program pascasarjana, dapat dipetakan model kepemimpinan yang berkembang atau digunakan ditunjukkan pada Gambar 1 .

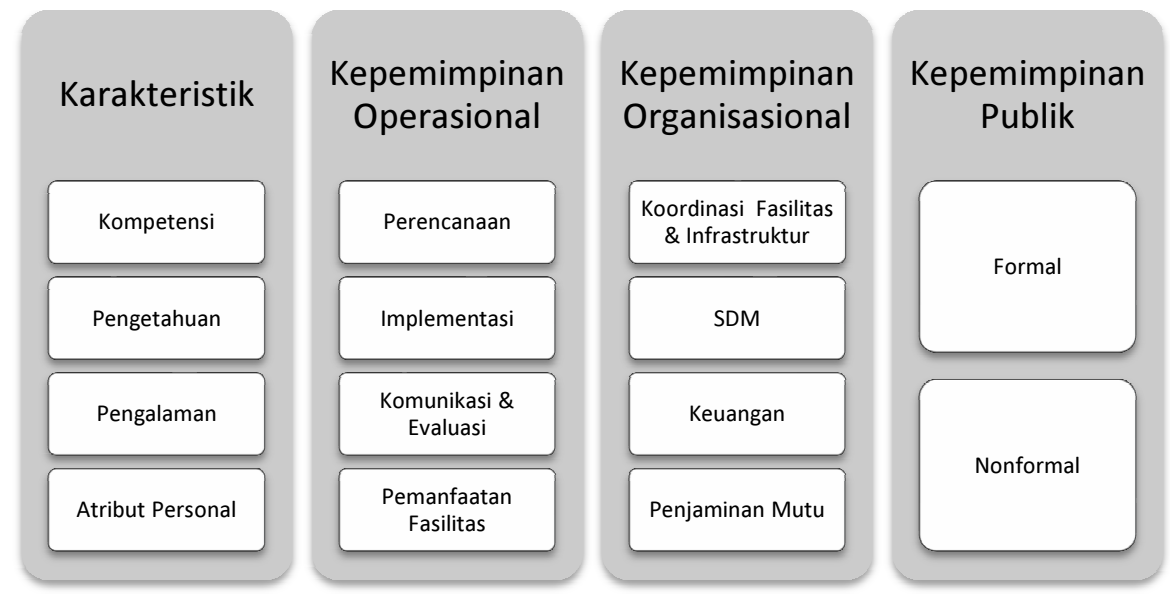

Gambar 1. Model Kepemimpinan di program pascasarjana UAD

\section{Kesimpulan}

Berdasarkan pada hasil dan diskusi yang dilakukan beberapa hal penting yang dapat dituliskan sebagai kesimpulan dalam identifikasi model kepemimpinan di pasca sarjana yang dapat juga digunakan pada pengelolaan institusi pendidikan tinggi secara umum adalah bahwa penentuan personi yang mempertimbangkan kompetensi, pengetahuan, pengalaman dan atribut personal akan dapat 
mempengaruhi kinerja dan peran kepemimpinan operasional, organisasional, dan publik. Aktivitas yang bersifat lintas departemen dan juga dengan pihak eksternal menjadi fokus bagi kepemimpinan dalam mencapai visi dan misi organisasi.

\section{Referensi}

Bass, B.M., Avolio, B.J., Jung, D.I. and Berson, Y. (2003), "Predicting Unit Performance by Assessing Transformational and Transactional Leadership", Journal of Applied Psychology, Vol. 88, No. 2, 207-218.

Bono, J.E. and Judge, T.A. (2004), "Personality and Transformational and Transactional Leadership: A Meta-Analysis", Journal of Applied Psychology, Vol. 89, No. 5, 901-910.

Cano, M.D. (2011), “Students' Involvement in Continuous Assessment Methodologies: A Case Study for a Distributed Information Systems Course", IEEE Transactions on Education, Volume: 54 Issue: 3 , pp. $442-451$.

Craig, R.J. and Amernic, J.H. (2006), "PowerPoint Presentation Technology and the Dynamics of Teaching”, Innov High Educ (2006) 31: 147-160.

Cranfield, D.J. and Taylor, J. (2008), "Knowledge Management and Higher Education: A UK Case Study”, The Electronic Journal of Knowledge Management, Vol. 6 Issue 2, pp. 85 - 100.

Koen, M.P., and Bitzer, E.M. (2010), "Academic Leadership In Higher Education: A "Participative" Perspective", Fromone Institution, Volume 8 Issue 1.

Leisyte, L., Enders, J. and de Boer, H. (2009), "The balance between teaching and research in Dutch and English universities in the context of university governance reforms", High Educ (2009) 58:619-635.

Lievens, F. ,Van Geit, P., and Coetsier, P. (1997), Identification of Transformational Leadership Qualities: An Examination of Potential Biases, European Journal Of Work and Organizational Psychology, 1997, 6 (4), 415-430.

Rienties, B., Beausaert, S., Grohnert, T., Niemantsverdriet, S. and Kommers, P. (2011), "Understanding academic performance of international students: the role of ethnicity, academic and social integration", Higher Education: The International Journal of Higher Education Research, published online 24 July 2011.

Shephard. K. (2008), "Higher education for sustainability: seeking affective learning outcomes", International Journal of Sustainability in Higher Education, Vol. 9 No. 1, 2008, pp. 87-98

Singh, A., and Purohit, B. (2010), "Leadership for Higher Education - Role of a Dean”, Academic Leadership The Online Journal, Volume 8 Issue 4

Yeh, Y.M. (2005), “ The Implementation of Knowledge Management System in Taiwan's Higher Education”, Journal of College Teaching \& Learning, Vol. 2 No.9, pp. 35-42. 